\title{
The seismic design suggestions of girder bridge
}

\author{
H. LI \& W. TANG \\ The School of Architecture \& Civil Engineering, Inner Mongolia University of Science and \\ Technology, Baotou, Inner Mongolia, China, hongli_1129@163.com
}

KEYWORD: Bridge Seismic damage; Aseismic design; Girder bridge

ABSTRACT: This article mainly analyses different representations of bridge seismic damage and their causes, discuss mostly the analytic means of bridge structures' elastic-plastic earthquake response and the design method of ductile earthquake-resistance. In the end, the developing trends of the method in future are introduced, the suggestions of modifying the specification are given.

\section{INTRODUCTION}

Along with the rapid development of economy and science, population distribution gradually concentrated in the city.

A lot of parts of China are located on areas where seismic activities are higher, the direct economic 1 osses caused earthquake are number hundreds of millions, while indirect losses caused by the destro $y$ of traffic and other facilities are uncountable. Once a bridge loses its function because of the earth quake, especially to a key bridge, a paralysis of traffic seriously direct and indirect economic losses will be brought. So, when the earthquake happens, how to ensure a safe and reliable bridge operatio $\mathrm{n}$, reduce the loss of life and economy to the minimum, and avoid a too conservative design, to be a $\mathrm{n}$ important issue that all the engineers concerned.

In order to make a effective design plan and to determine the reinforcement measures, we should have a clear understanding of the professional field. Making a systematically study and classification is one of the very best ways.

As the saying goes "the former's mistake is the latter's lesson", so the analyzing based on the site investigation of the seismic damage to bridges is quite necessary to develop bridge seismic design principle and design details.

\section{COMMON BRIDGES SEISMIC DAMAGES AND THEIR REASONS}

Analyzing the bridge seismic damages and there reasons is and important way for us to establish the correct seismic design method and develop effective earthquake resisting methods. According to the reference materials and earthquake damage examples, the bridge seismic damages can be classified as follows:

\section{Damages of structure for support and connection ( bridge bearings)}

Bridge bearings as structures for support and connection are often be damaged, such as the damaged bearings in great Hanshin earthquake were up to $28 \%$. The destruction of the bearing will change the way power transmission, therefor seismic performances of other structural members would be effected. The main failure modes of bearings are support displacement, fracture of anchor bolt, the sliding of freely movable bearing, etc. When the shearing strength exceed the limit, the bridge bearing would be teared. When the shear deformation exceed the limit, girder-bearing relative slippage even girder falling would be caused. 


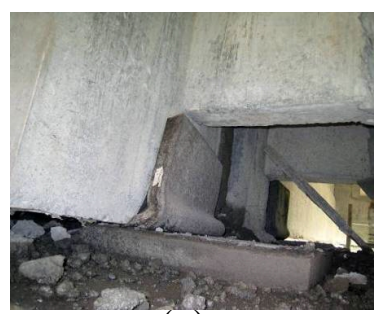

(a)

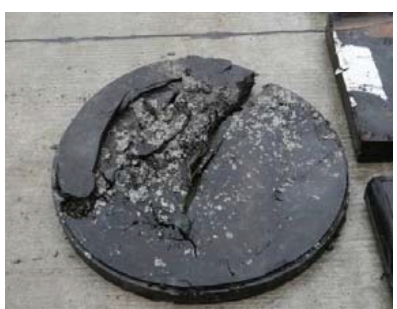

(b)

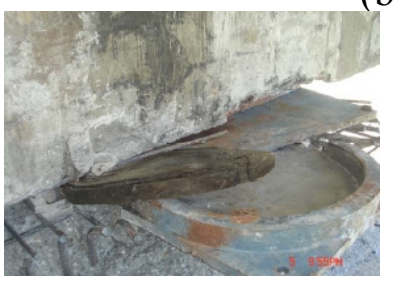

(c)

Fig 1. Tearing failure of bearing

\section{Over-displacement of superstructures}

The over-displacement of superstructures refers to the seismic damages caused by the longitudinal and lateral displacement/torsion of bridge superstructure, which were commonly occurred around expansion joint. ${ }^{[1]}$ The expression form of one of this seismic damages were dislocation and extrusion between girders, and another form was the unseating of superstructures, caused by the large displacement exceeds the bearing surface of piers and abutments. Girder-bearing relative slippage were much more common than girder falling in seismic area. Because of the absence of horizontal restraint between girders and piers, relative displacements would easily occurred when the horizontal seismic force exceed the friction and shear capacity of the bearings. The transverse displacement of beam on pier No.3 of Baishuixi Bridge had been reached $48 \mathrm{~cm}$ in the China Wenchuan earthquake, as shown in Figure 2. In addition, the existence of blocks could reduces the risk of girder-falling, which also been damaged when the earthquake strikes, as shown in Figure 3.

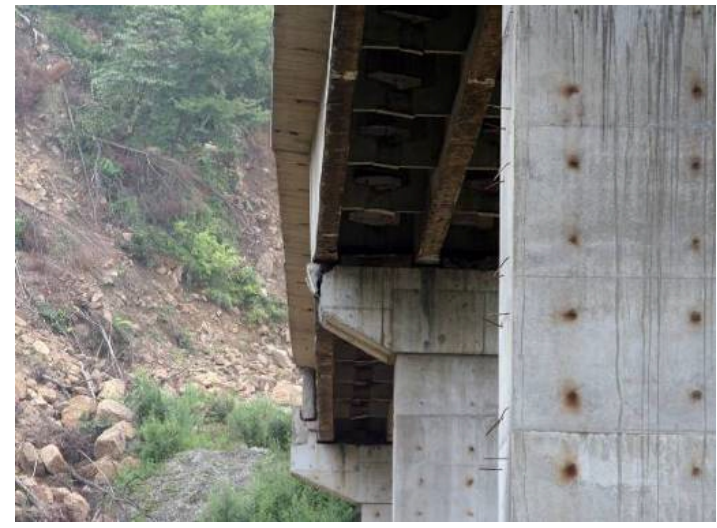

Fig 2. Transverse displacement of beam on pier

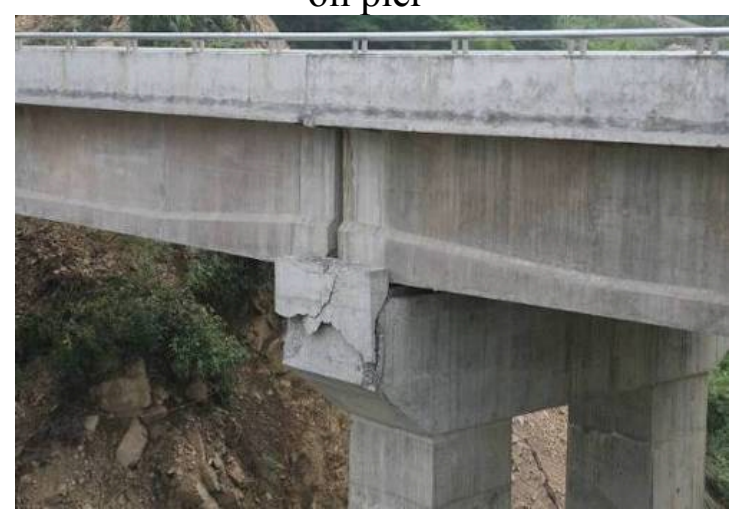

No.3 of Baishuixi Bridge
The unseating of bridge superstructure is one of the most serious earthquake damage of girder bridges. The statistical data showed that girder-falling in vertical direction were much more than horizontal direction(almost five to six times). Because of the much bigger energy would be produced by the impact between the girder-falling in vertical direction and the walls of piers than by the shaking of girder on the piertop. Most of the seismic damages of superstructures were occurred both at once. For example, there were lots of pier-inclines caused by the impact of the dropped girder during Wenchuan earthquake.

\section{Seismic damages of substructure}

As a primary supporting member, piers are easily been destroyed because of the structure with rigid upper girders and flexible bottom. The earthquake damage mainly includes shear failure, conquassation and cracking of pier bodies and cracking, lateral displacement and incline of cross tie beams. Some bridge collapsed because of severely destructive of their pier and abutment, which caused by the larger horizontal force and the reversal vibration by earthquake occurred on the relatively weak section.

Anecdotal evidence ${ }^{[2]}$ suggests that, the larger slenderness flexible piers are often shown as bending 
failure, called ductile failure, and the specific performances were cracking of concrete, partially exposed or bending of the steels, and large plastic deformation. This failure is often caused by the insufficient of restriction hoop and the weakness of the steel welding, as shown in Figure 4 . The the thick and short piers with small slenderness were often manifest as shear failure, called brittle failure, characterized by the large cracks in concrete and the clipping of the steels. This failure is often caused by the inadequacy shear strength of piers, as shown in Figure 5.

The seismic damages of abutment manifestations included not only the overturn and slippage of abutment caused by the slope slipping, the sand liquefaction and uneven settlement of foundation, but also the against damage of the superstructure. The hidden nature of the foundation damage means its impact is often undetectable and underestimated and is not easy to be repaired.

It shows from a lot of analyses that, causes of damage to Bridges can be roughly classified into the following three:

A.The earthquake intensity exceed the seismic fortification criterion.

B.The selection of site for bridge to be detrimental to the anti-seismic.

C.The improper design and construction caused by human reason made the structure lack of seismic capacity.

\section{Further design improvement according to the continuous girder bridge}

The effect degree of each factor for seismic response of large-span continuous girder bridge

(1) With the increase of pier height, the increment of girder and pier bottom stress gradually reduced, the relative displacement of beam-end and pier-top deflection gradually increased.

(2) As the span increases, the girders' mid-span moment and the fixed piers' bottom moment decreases first and then increases, the girders' moment at shifting

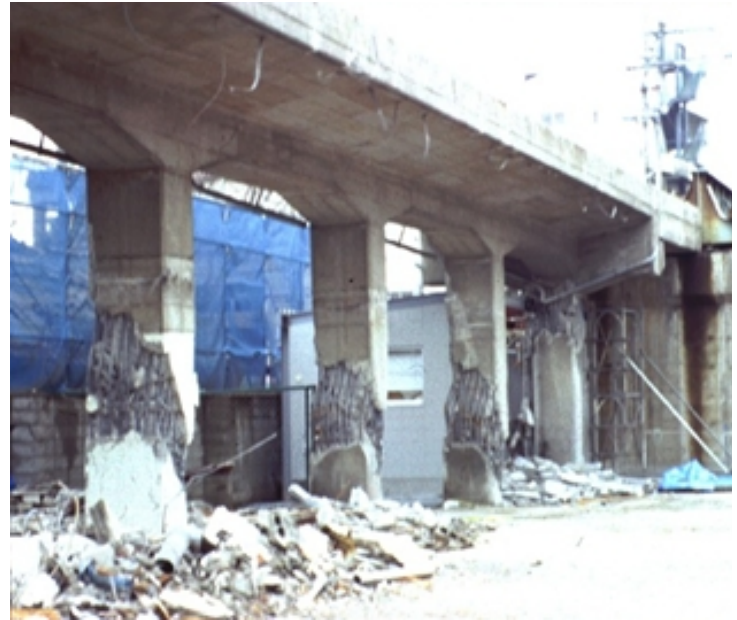

Fig 4 . The crush and explosive spalling of the concrete

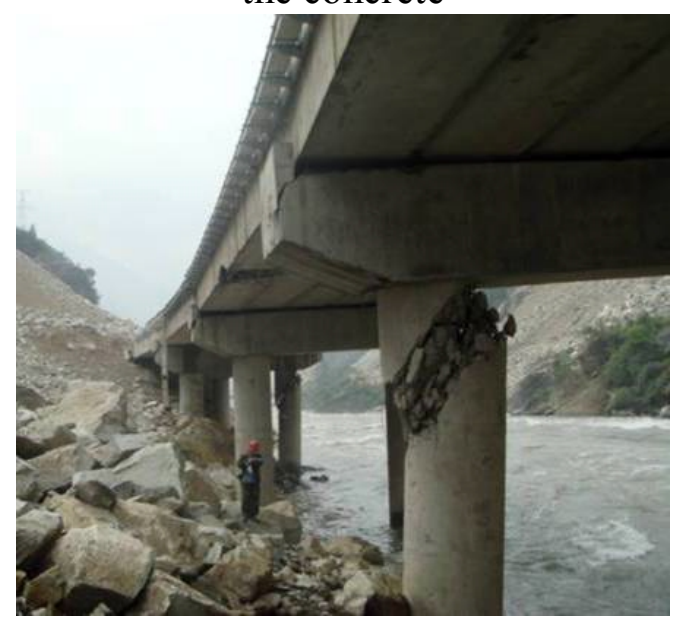

Fig 5. The shear failure of the piers bearing section gradually increases, the girders' shearing force at fixed bearing increases at first then decreases, and the longitudinal displacement increases.

(3) The height variations of piers were more sensitive to the impact of beam-end deflection, the beam stress and the fixed pier internal force. By attending to the transformation and adjusting appropriately, the seismic behavior of the structure will obtain excellent results.

(4) Along with an increasing of span number, the relative displacement between beam-end and piertop increases, the shearing force and bending moment in axial direction of fixed pier bottom decreases.

(5) With the increase of fixed piers' stiffness, the relative displacement between beam-end and piertop decreases to some degree and then bounces, the internal force of girders and fixed piers increases. So a smaller stiffness of fixed pier is a positive factor for seismic-isolation structures.

(6) The internal force of girders and fixed piers would be decreased as horizontal restrain weakens, while the influence to the displacement was not obvious.

\section{The seismic design recommendations of concrete continuous girder bridge}

Through the analysis with the bridge earthquake damage and the seismic behavior of the continuous girder bridge, the seismic design recommendations are presented as follows: 
(1) We had different objectives and content of seismic design in different phases. In the phase of specific feasibility research, our general seismic design policy is to place conceptual design first, calculation and structural design second. In the phase of preliminary design phase, the system design should be the first and the structural design should be the second. And in the phase of construction documents design phase, the structural design should be the first.

(2) Attaches great importance to the seismic concept design of the structure of the bridge. In order to avoid the damage effect on the bridges by earthquakes, geological and topographic conditions should be considered while bridge site and foundation forms is selected.

(3) The safety estimation of earthquake resistant should be carried out, even more, seismic fortification criterion of long span bridges should be raised. For example, design reference period could be increased from 50 years to 100 years, therefore excess probability levels remain unchanged and reoccurrence period can be increased by double ${ }^{[2]}$.

Table 1. The reoccurrence period of design reference period

\begin{tabular}{lll}
\hline $\begin{array}{l}\text { excess probability } \\
(\%)\end{array}$ & \multicolumn{2}{c}{ design reference period (year) } \\
50 & 100 \\
\hline 63.2 & 50 & 100 \\
10 & 475 & 3283 \\
2 & 2475 & 4950 \\
\hline
\end{tabular}

(4) Change from "seismic design" to "seismic isolation design" is much more significant for large important bridge.

(5) More attention should be taken on the bridge piers and foundations' ductile earthquakeresistance design and checking calculation.

(6) The traditional method of the aseismatic design of bridge is to ensure the structure to have enough intensity and ductility to resist earthquake, which is turning into the performance-based design or displacement-based design. During the course of the seismic design for the bridge pier's ductility, the seismic effect to the shear strength and dealing with the antinomy of the plastic deformation ability and structural damage is concerned deeply.

(7) The structure design of decreasing vibration, separating vibrationthe is the pursuit of innovative ideas of the majority of researchers. In order to ensure earthquake safety of the structure, to study the performance of the isolation system and hysteretic damper is of great social significance and economic benefits.

\section{Suggestions for improvement of current seismic code in China}

\section{Allowing the bridge bearings are damaged first during the design.}

Although the structural styles and the force conducting ways of the Chinese bridges are quite different from the abroad ones, quite few attention have been payed to the differences when the ongoing specification is established. The most obvious example is the bridge bearings' forms, which in China are often to be the laminated rubber ones, in Japan are often to be the steel ones, while in the USA frame-type piers with no bearings are more commonly. So we cannot establishing specifications based on foreign experiences. ${ }^{[3]}$ According to the situation of our country, we could allow the bridge bearings are damaged first during the design, which can dissipate the seismic energy.

Bridge seismic construction measures should be divided by importance of bridge and seismic hazard, not intensity.

The requirement of the 3-level earthquake-resistance design is too general. Hence, the author of this paper proposes that different design goals should be set according to the different earthquake magnitudes and parts of the structure. In order to design personnel to better determine, the strength and the ductility index of the major component, such as pile foundation, cushion cap, bent cap, bearing and block in different earthquake levels should be clearly posted. Most of all, considering emergency measure must be taken after a sudden earthquake event bridge seismic construction measures should be divided by importance of bridge and seismic hazard, not intensity. 


\section{REFERENCES:}

[1] Kuanhou Yang. Seismic performance evaluations and seismic retrofits of municipal bridges (In Chinese)[D]. Beijing: Beijing institute of civil engineering and architecture, 2012.

[2] Guofeng Xu. Preliminary study on ductile seismic design of continuous beam bridges in high seismic intensity zone (In Chinese)[D].Chongqing: Chongqing Jiaotong University, 2009.

[3] Wancheng Yuan, Lichu Fan. Ductility and isolation in aseismic designs for bridges-development tendency of Chinese aseismic code for bridges from the view of Eurocode 8(In Chinese)[J]. Journal of Tongji University, 1994, Vol. 22, No. 4. 